\title{
Plantas de cobertura submetidas a diferentes fontes de fósforo em solos distintos
}

\section{Cover crops under different sources of phosphorus in different soils}

\author{
Tácio Oliveira da Silva ${ }^{1 *}$; Antônio Eduardo Furtini Neto²; Leandro Flávio \\ Carneiro ${ }^{3}$; Vinitius Paludo ${ }^{4}$
}

\section{Resumo}

O objetivo deste trabalho foi avaliar a biomassa e absorção de fósforo por espécies vegetais de cobertura submetidas a fontes de fósforo em solos distintos. O experimento foi realizado em casa de vegetação no Departamento de Ciência do Solo da Universidade Federal de Lavras. Utilizou-se o delineamento inteiramente casualizado, em esquema fatorial $5 \times 2 \times 2$, sendo cinco forrageiras (Brachiaria decumbens, Brachiaria brizantha cv. Marandu, Panicum maximum cv. Tanzânia, Avena strigosa - aveia preta cv. Comum e Lupinus albus L.- tremoço cv. Comum), duas fontes de fósforo (superfosfato triplo - ST e fosfato natural de araxá - FNA) e dois tipos de solos (LATOSSOLO VERMELHO Distroférrico - LVdf e NEOSSOLO QUARTZARÊNICO - RQo), com quatro repetições. As doses de fosfatos utilizadas foram 90 e $50 \mathrm{mg} \cdot \mathrm{dm}^{-3}$ de $\mathrm{P}$, baseado no $\mathrm{P}_{2} \mathrm{O}_{5}$ total, respectivamente no LVdf e no RQo. A colheita foi realizada aos 70 dias após a emergência das plântulas. O ST proporcionou maior valor de matéria seca da parte aérea, das raízes e acúmulo de $\mathrm{P}$ e índice de utilização de $\mathrm{P}$ pelas plantas de cobertura nos solos estudados. A aveia preta, com aplicação de ST e o tremoço com o FNA mostraram-se promissores na produção de cobertura vegetal e ciclagem de fósforo.

Palavras-chave: Forrageiras, leguminosas, gramíneas, ciclagem de fósforo, eficiência de utilização de

\begin{abstract}
This work aimed to evaluate biomass production and phosphorus uptake by cover crops growing in two different soil types fertilized with two different sources of phosphorus. The experiment was carried out under greenhouse condition, at the Department of Soil Science, Federal University of Lavras. The experimental set up was a completely randomized design, in a $5 \times 2 \times 2$ factorial scheme, testing five cover crops (Brachiaria decumbens, Brachiaria brizantha cv. Marandu, Panicum maximum cv. Tanzania, Avena strigosa - oat cv. Common and Lupinus albus L. - lupine cv . Common), two P fertilizers (triple superphosphate - ST and rock phosphate araxá - FA), and two soil types (Oxisol - LVdf and Entisol - RQo), with four replications. Doses of phosphate used were 90 and $50 \mathrm{mg} \cdot \mathrm{dm}^{-3}$ of $\mathrm{P}$, based on the total $\mathrm{P}_{2} \mathrm{O}_{5}$ in LVdf and RQo, respectively. Plants were harvested 70 days after seedling emergence. In both soils, shoot and root biomass was higher in the ST treatment than in FNA treatment. This was probably due to the higher P accumulation in the plants. Satisfactory vegetative cover was observed when oat was cultivated using ST as a P source. For lupine, best results were obtained using FA as a P source.
\end{abstract}

Key words: Fodder, legumes, grass, phosphorus cycling, efficiency of utilization of phosphorus

\footnotetext{
${ }_{1}$ Eng $^{\circ}$ Agr $^{\circ}$, Prof. Adjunto, Dept ${ }^{\circ}$ de Engenharia Agronômica, DEA, Universidade Federal de Sergipe, UFS. 49100-000, São Cristóvão, SE. E-mail: tacios@ufs.br

2 Eng ${ }^{\circ}$ Agr $^{\circ}$, Prof. Associado, Departamento de Ciência do Solo, DCS, Universidade Federal de Lavras, UFLA. CP 3037, $37200-$ 000, Lavras, MG. Bolsista do CNPq. E-mail: afurtini@dcs.ufla.br

3 Eng ${ }^{\circ}$ Agr $^{\circ}$, Prof. Adjunto, Universidade Estadual de Mato Grosso do Sul, UEMS. 79540-000, Cassilândia, MS. E-mail: leoflacar@ yahoo.com.br

4 Eng ${ }^{\circ}$ Agro $^{\circ}$, Rua Afonso Pena, 568, Apto 402, Centro, Unaí, MG, 38610-000. E-mail: vinitiuspaludo@yahoo.com.br

* Autor para correspondência
} 


\section{Introdução}

$\mathrm{O}$ fornecimento de fósforo representa parte expressiva do custo de produção das culturas, especialmente nas regiões tropicais e na quase totalidade nos solos da região do cerrado brasileiro, pois além de apresentarem baixa disponibilidade de fósforo (P), são intemperizados, ácidos, argilosos e oxídicos, características que favorecem a fixação do fósforo pelo solo. A implicação prática disso é que, embora a exigência de fósforo pelas plantas não seja elevada, grandes quantidades do nutriente devem ser fornecidas nas adubações para promover alguma saturação do solo e originar um excedente que atenda aos requerimentos nutricionais das culturas (NOVAIS; SMYTH, 1999).

A maior parte do custo com a implantação de uma lavoura na região do cerrado brasileiro está relacionada com a correção da acidez do solo e com a adubação fosfatada (ARAÚJO; SAMPAIO; MEDEIROS, 2005). Considerando a essencialidade do fósforo para o desenvolvimento das plantas, e os fosfatos um recurso natural não renovável, deve-se buscar formas de utilizá-lo eficientemente. Uma prática que resulta em aumento na recuperação do $\mathrm{P}$, adicionado ao solo, é a implantação de um sistema de rotação de culturas, incluindo espécies com alta eficiência em extrair e utilizar o P. Plantas que possuem mecanismos estruturais, bioquímicos e fisiológicos, que permitam um maior aproveitamento do fósforo do solo podem ser utilizadas para se alcançar uma alta eficiência agronômica da adubação fosfatada (FERNANDES; MURAOKA, 2002; SOUSA; LOBATO; REIN, 2004).

Os resíduos das culturas e das plantas de cobertura contêm quantidades consideráveis de $\mathrm{P}$ em seus tecidos, que mediante sua mineralização poderão atender boa parte da demanda das culturas (BORKERT et al., 2003). No processo de mineralização dos resíduos orgânicos ocorre a formação de formas orgânicas de $\mathrm{P}$ menos suscetíveis às reações de adsorção. $\mathrm{O}$ solo pode adsorver ácidos orgânicos com grande energia, competindo com os sítios de adsorção de $\mathrm{P}$ e aumentando a disponibilidade desse nutriente para as plantas (OLIVEIRA et al., 2002; ANDRADE et al., 2003).

Estudos têm demonstrado que as plantas com maior capacidade de extrair o fósforo são aquelas que possuem sistema radicular abundante e que produzem exudatos capazes de acidificar a rizosfera, favorecendo a solubilização dos fosfatos naturais menos reativos, insolúveis em água, que necessitam de acidez para que alguma dissolução se inicie. Outro fator que favorece a solubilidade dos fosfatos naturais é o dreno de $\mathrm{Pe}$ de $\mathrm{Ca}$ pelas plantas. Uma maior remoção de Ca e P faz com que aumente a taxa de dissolução do fosfato natural. Condições que favoreçam o aumento da CTC com um maior teor de matéria orgânica e calagem; além da própria cultura podem exercer papel preponderante na eficiência dos fosfatos naturais, uma vez que atuariam como dreno de Ca (NOVAIS; SMYTH, 1999; SILVA et al., 2009).

As plantas de cobertura, além de protegerem o solo dos agentes climáticos, seqüestram $\mathrm{C}$ atmosférico e, desta forma, apresentam potencial para manter ou elevar o teor de matéria orgânica, mobilizar e reciclar nutrientes. A sincronização entre espécies vegetais, solos e o fósforo constituem uma ferramenta indispensável para o melhor aproveitamento desse elemento por diferentes espécies, maximizando à resposta da planta a adubação fosfatada na maioria dos solos tropicais (PERIN, 2001; DUDA et al., 2003; ANDRADE et al., 2003; SOARES; LIMA; CRISÓSTOMO, 2007).

O presente trabalho teve como objetivo avaliar a biomassa, absorção e utilização de fósforo por espécies vegetais de cobertura submetidas a fontes de fósforo em solos distintos.

\section{Material e Métodos}

O experimento foi conduzido em condição de casa de vegetação no Departamento de Ciência do Solo da Universidade Federal de Lavras (UFLA). Os solos utilizados como substrato foram um LATOSSOLO VERMELHO Distroférrico (LVdf) e um NEOSSOLO QUARTZARÊNICO (RQo), ambos coletados na 
camada de 0 - $20 \mathrm{~cm}$ de profundidade, em condições naturais. As amostras de solo foram secas ao ar, destorroadas e passadas em peneira de $4 \mathrm{~mm}$ de abertura de malha. Subamostras desses solos foram tamisadas em peneira de $2 \mathrm{~mm}$ de abertura de malha, constituindo a terra fina seca ao ar (TFSA) para a caracterização química e física (Tabela 1).

Tabela 1. Atributos químicos e físicos do LATOSSOLO VERMELHO Distroférrico (LVdf) e do NEOSSOLO QUARTZARÊNICO (RQo), antes da aplicação dos tratamentos.

\begin{tabular}{|c|c|c|}
\hline \multirow[t]{2}{*}{ Atributos } & \multicolumn{2}{|c|}{ Solos } \\
\hline & LVdf & RQo \\
\hline $\mathrm{pH}\left(\mathrm{H}_{2} \mathrm{O}\right)$ & 4,9 & 5,2 \\
\hline $\mathrm{P}-$ Mehlich -1 $\left(\mathrm{mg} \mathrm{dm}^{-3}\right)^{1}$ & 0,6 & 1,2 \\
\hline $\mathrm{P}$ - remanescente $\left(\mathrm{mg} \mathrm{L}^{-1}\right)^{2}$ & 5,2 & 21,7 \\
\hline $\mathrm{K}\left(\mathrm{cmolc} \mathrm{dm}^{-3}\right)$ & 0,094 & 0,013 \\
\hline $\mathrm{Ca}^{2+}\left(\mathrm{cmolc} \mathrm{dm}^{-3}\right)$ & 0,4 & 0,4 \\
\hline $\mathrm{Mg}^{2+}\left(\mathrm{cmolc} \mathrm{dm}^{-3}\right)$ & 0,2 & 0,2 \\
\hline $\mathrm{Al}^{3+}\left(\mathrm{cmolc} \mathrm{dm}^{-3}\right)$ & 1,4 & 1,1 \\
\hline $\mathrm{H}+\mathrm{Al}\left(\mathrm{cmolc} \mathrm{dm}^{-3}\right)$ & 9,8 & 2,6 \\
\hline $\mathrm{SB}\left(\mathrm{cmolc} \mathrm{dm}^{-3}\right)^{3}$ & 0,7 & 0,6 \\
\hline $\mathrm{t}\left(\mathrm{cmolc} \mathrm{dm}^{-3}\right)^{4}$ & 2,1 & 1,7 \\
\hline $\mathrm{T}\left(\mathrm{cmolc} \mathrm{dm}^{-3}\right)^{5}$ & 10,5 & 3,2 \\
\hline$V(\%)^{6}$ & 6,6 & 19,0 \\
\hline M.O. $\left(\mathrm{g} \mathrm{kg}^{-1}\right)^{7}$ & 6,3 & 1,3 \\
\hline $\mathrm{m}(\%)^{8}$ & 67,0 & 64,0 \\
\hline $\mathrm{Zn}\left(\mathrm{mg} \mathrm{dm}{ }^{-3}\right)$ & 0,9 & 0,5 \\
\hline $\mathrm{Fe}\left(\mathrm{mg} \mathrm{dm}^{-3}\right)$ & 182,7 & 108,4 \\
\hline $\operatorname{Mn}\left(\mathrm{mg} \mathrm{dm}^{-3}\right)$ & 4,9 & 2,6 \\
\hline $\mathrm{Cu}\left(\mathrm{mg} \mathrm{dm}^{-3}\right)$ & 1,2 & 0,4 \\
\hline $\mathrm{B}\left(\mathrm{mg} \mathrm{dm}^{-3}\right)$ & 0,9 & 0,1 \\
\hline $\mathrm{S}-\mathrm{SO}_{4}^{2-}\left(\mathrm{mg} \mathrm{dm}^{-3}\right)$ & 4,9 & 3,3 \\
\hline Areia $\left(\mathrm{g} \mathrm{kg}^{-1}\right)$ & 90,0 & 920 \\
\hline Silte $\left(\mathrm{g} \mathrm{kg}^{-1}\right)$ & 100,0 & 10 \\
\hline Argila $\left(\mathrm{g} \mathrm{kg}^{-1}\right)$ & 710,0 & 70 \\
\hline
\end{tabular}

${ }^{1} \mathrm{P}$ e $\mathrm{K}=$ extrator Mehlich- $1 ;{ }^{2} \mathrm{P}$-rem = fósforo remanescente; $\mathrm{Ca}, \mathrm{Mg}$ e $\mathrm{Al}$ = extração com $\mathrm{KCl}$ mol L ${ }^{-1} ; \mathrm{H}+\mathrm{Al}$ (acidez potencial $)=$ acetato de $\mathrm{Ca} 0,5 \mathrm{~mol} \mathrm{~L}{ }^{-1} \mathrm{pH} \mathrm{7,0;}{ }^{3} \mathrm{SB}=$ soma de bases; ${ }^{4} \mathrm{t}=\mathrm{CTC}$ efetiva; ${ }^{5} \mathrm{~T}=\mathrm{CTC}$ a pH 7,$0 ;{ }^{6} \mathrm{~V}=$ saturação por bases; ${ }^{7} \mathrm{MO}=$ matéria orgânica; ${ }^{8} \mathrm{~m}=$ saturação por $\mathrm{Al} ; \mathrm{Zn}, \mathrm{Fe}$, $\mathrm{Mn}$ e $\mathrm{Cu}=$ extrator Mehlich-1; $\mathrm{B}=$ extração em água quente. 
O delineamento experimental utilizado foi o inteiramente casualizado em um esquema fatorial $5 \times 2 \times 2$, com quatro repetições. Os tratamentos consistiram em cinco espécies de cobertura vegetal [Brachiaria decumbens, Brachiaria brizantha cv. Marandu, Panicum maximum cv. Tanzânia, Aveia preta (Avena stringosa) cv. comum e Tremoço cv. Comum (Lupinus Albus)], duas fontes de fósforo [superfosfato triplo (ST) e fosfato natural de araxá (FNA)], com 46,1 e 22,7\% de $\mathrm{P}_{2} \mathrm{O}_{5}$ total, respectivamente e dois tipos de solo (LATOSSOLO VERMELHO Distroférrico - LVdf e NEOSSOLO QUARTZARÊNICO - RQo). Antes da aplicação dos tratamentos foi realizado a correção da acidez dos solos com aplicação de calcário dolomitico calcinado e micropulverizado com 35, 14 e 100\% de $\mathrm{CaO}, \mathrm{MgO}$ e PRNT, respectivamente. Os solos ficaram incubados por um período de 20 dias e a dose de calcário foi calculada para elevar a saturação por bases (V) para 50\%, mantendo-se a umidade em $60 \%$ do volume total de poros, através da pesagem diária dos vasos de $1,5 \mathrm{dm}^{-3}$. O volume de solo utilizado foi com o intuito de avaliar a potencialidade das plantas em absorver o fósforo das fontes aplicadas.

A quantidade de cada fonte de $\mathrm{P}$ aplicada foi calculada com base no teor de $\mathrm{P}_{2} \mathrm{O}_{5}$ total dos fertilizantes fosfatados, $\mathrm{e}$ as doses de $\mathrm{P}$ corresponderam a $90 \mathrm{mg} \cdot \mathrm{dm}^{-3}$ de $\mathrm{P}_{2} \mathrm{O}_{5}$ para o LATOSSOLO VERMELHO Distroférrico (LVdf) e $50 \mathrm{mg} \cdot \mathrm{dm}^{-3} \mathrm{P}_{2} \mathrm{O}_{5}$ para o NEOSSOLO QUARTZARÊNICO (RQo).

Concomitantemente à aplicação do fósforo, realizou-se a adubação básica com os demais nutrientes através das fontes de sais p.a. As doses de macro e micronutrientes consistiram em: $150 \mathrm{mg}$ de N; $150 \mathrm{mg}$ de $\mathrm{K} ; 40 \mathrm{mg}$ de $\mathrm{S} ; 5 \mathrm{mg}$ de Zn; 1,5 $\mathrm{mg}$ de $\mathrm{Cu} ; 3,6 \mathrm{mg}$ de $\mathrm{Mn} ; 0,8 \mathrm{mg}$ de B; 0,15 mg de Mo por $\mathrm{dm}^{3}$ de solo, sendo aplicados em solução e misturados aos solos para melhor uniformização. As fontes utilizadas foram o $\mathrm{NH}_{4} \mathrm{NO}_{3}, \mathrm{~K}_{2} \mathrm{SO}_{4}$, $\mathrm{ZnSO}_{4} .7 \mathrm{H}_{2} \mathrm{O}, \quad \mathrm{CuSO}_{4} .5 \mathrm{H}_{2} \mathrm{O}, \quad \mathrm{MnSO}_{4} ; \mathrm{H}_{3} \mathrm{BO}_{3}$; $\left(\mathrm{NH}_{4}\right)_{6} \mathrm{Mo}_{7} \mathrm{O}_{24} \cdot 4 \mathrm{H}_{2} \mathrm{O}$. As adubações com $\mathrm{N}$ e $\mathrm{K}$ foram diferenciadas de acordo com o crescimento e necessidade das forragens. Logo após a aplicação dos fertilizantes, os solos permaneceram incubados por um período de 15 dias, mantendo-se a umidade dos vasos a $60 \%$ do volume total de poros (VTP), através de pesagens diárias dos vasos.

A semeadura das gramíneas e da leguminosa (tremoço) consistiu de aproximadamente 20 sementes por vaso. Após 10 dias do início da germinação, procederam-se os desbastes, deixandose quatro plantas por vaso, levando em consideração $\mathrm{o}$ vigor e uniformidade das plântulas. $\mathrm{O}$ número de plantas por vaso teve o intuito de verificar a máxima absorção de fósforo das fontes aplicadas nos solos.

No momento da colheita, 70 dias após o plantio, procedeu-se ao corte das plantas rente ao solo, separando-as em parte aérea e raiz. A biomassa vegetal após a colheita foi seca em estufa de circulação forçada de ar, à $65^{\circ} \mathrm{C}$, até obtenção da massa constante, determinando-se a massa seca da parte aérea e raiz, posteriormente, a parte aérea foi moída em moinho tipo Willey. Os teores foliares de $\mathrm{P}$ foram extraídos por digestão nítrico-perclórica (MALAVOLTA; VITTI; OLIVEIRA, 1997). A concentração de $\mathrm{P}$ no extrato foi determinada por colorimetria (BRAGA; DEFELIPO, 1974). Determinou-se o acúmulo do $\mathrm{P}$ na parte aérea das plantas de cobertura, pelo produto da massa seca e o teor de P. O índice de eficiência de utilização de fósforo (IEU) pelas espécies vegetais foi calculado de acordo com Siddiqi e Glass (1981) onde: IEU = massa seca da parte aérea ${ }^{2}\left(\mathrm{MS}^{2}\right)$ / conteúdo total de P (CP). Determinou-se também a relação parte aérea e raiz com os dados da biomassa.

Os dados relativos ao crescimento e nutrição mineral das forrageiras foram analisados estatisticamente através da análise de variância, pelo teste $\mathrm{F}$ e, em seguida as médias foram comparadas pelo teste Tukey, ao nível de 5\% de probabilidade, com o auxílio do programa estatístico SISVAR (FERREIRA, 2000). 


\section{Resultados e Discussão}

\section{Latossolo vermelho distroférrico ( $L V d f)$}

Observou-se que com a aplicação do fosfato de Araxá (FNA), não houve diferença entre as forrageiras na produção de massa seca da parte aérea (MSPA) e nem da raiz (MSR). Porém, com o uso do superfosfato triplo (ST) no vaso com aveia preta, obteve-se a maior produção de MSPA, seguida da Brachiaria decumbens. O incremento da MSPA da aveia preta em relação B. brizantha, B. decumbens, Tanzânia e tremoço correspondeu a 73,7, 46,4, 84,6 e $131 \%$, respectivamente. Observou-se que a aplicação do ST em relação ao FNA proporcionou maior produção de MSPA e MSR, em todas as plantas de cobertura avaliadas (Tabela 2).

Tabela 2. Produção de massa seca na parte aérea (MSPA) e raiz (MSR) e a relação parte aérea/raiz (MSPA/ MSR) das plantas de cobertura sob fontes de P em um LATOSSOLO VERMELHO Distroférrico.

\begin{tabular}{|c|c|c|c|c|c|c|}
\hline \multirow[t]{2}{*}{ Forrageiras } & \multicolumn{2}{|c|}{ MSPA } & \multicolumn{2}{|c|}{ MSR } & \multicolumn{2}{|c|}{ MSPA/MSR } \\
\hline & ${ }^{2} \mathbf{S T}$ & ${ }^{3}$ FNA & ST & FNA & ST & FNA \\
\hline & \multicolumn{4}{|c|}{ 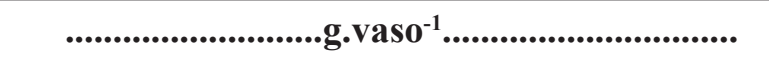 } & \multicolumn{2}{|c|}{--} \\
\hline Brachiaria brizantha & $8,88 \mathrm{bcA}^{1}$ & $1,04 \mathrm{aB}$ & $9,31 \mathrm{aA}$ & $0,76 \mathrm{aB}$ & $0,96 \mathrm{bA}$ & $1,36 \mathrm{cA}$ \\
\hline Brachiaria decumbens & $10,54 \mathrm{bA}$ & $1,21 \mathrm{aB}$ & $9,83 \mathrm{aA}$ & $0,68 \mathrm{aB}$ & $1,07 \mathrm{bB}$ & $1,81 \mathrm{cA}$ \\
\hline Tanzânia & $8,36 \mathrm{cdA}$ & $0,76 \mathrm{aB}$ & 8,76 aA & $0,54 \mathrm{aB}$ & $0,95 \mathrm{bA}$ & $1,43 \mathrm{cA}$ \\
\hline Aveia preta & $15,43 \mathrm{aA}$ & $1,35 \mathrm{aB}$ & $5,76 \mathrm{bA}$ & $0,49 \mathrm{aB}$ & $2,67 \mathrm{aA}$ & $2,82 \mathrm{bA}$ \\
\hline Tremoço & $6,68 \mathrm{dA}$ & $2,60 \mathrm{aB}$ & $2,51 \mathrm{cA}$ & $0,44 \mathrm{aB}$ & $2,65 \mathrm{aB}$ & $4,52 \mathrm{aA}$ \\
\hline
\end{tabular}

(1) Médias seguidas pela mesma letra minúscula na coluna e maiúscula na linha não diferem entre si pelo teste de Tukey, a 5\% de probabilidade. ${ }^{2} \mathrm{ST}$ - superfosfato triplo; ${ }^{3} \mathrm{FNA}$ - fosfato natural de araxá.

Sabe-se que as características de reatividade das fontes de $\mathrm{P}$ são de grande importância em relação à sua eficiência a curto prazo. Os fosfatos de maior reatividade, sendo mais prontamente disponíveis, favoreceram a absorção e o aproveitamento do nutriente pelas plantas, como foi observado no estudo de Bedin et al. (2003), avaliando crescimento da soja submetida a fontes de P puderam verificar que as fontes de maior solubilidade promoveu o maior aproveitamento do $\mathrm{P}$ pelas plantas de soja cultivadas em solos distintos (LATOSSOLO VERMELHO AMARELO e NEOSSOLO QUARTZARÊNICO).

Comportamento similar foi verificado em outros estudos, como o de Sarmento, Corsi e Campos (2001) ao avaliarem a produção de massa seca de alfafa, onde verificaram que as maiores produções de massa seca foram alcançadas, quando se utilizou a fonte de P de maior solubilidade (ST), quando comparada com o fosfato de Gafsa; e o de Corrêa et al. (2005), com superioridade do ST em relação ao fosfato de Gafsa na produção de massa seca da parte aérea do milho.

As gramíneas produziram maior MSR com o uso do ST, as quais foram seguidas pela aveia preta e tremoço (Tabela 2). Observa-se também que houve uma tendência de maior produção de MSR com o uso de FNA, embora sem significância estatística. Isso pode ser explicado pela eficiência de aquisição e utilização de P entre as forrageiras (RAO et al. 1997), uma vez que as gramíneas possuem um maior sistema radicular, resultando em maior produção de massa seca das raízes, enquanto as 
leguminosas têm maior eficiência de aquisição de $\mathrm{P}$ por unidade de raiz (FOHSE; CLASSEN; JUNGK, 1988; RAGHOTHAMA, 1999).

É interessante ressaltar que com o uso do FNA, o tremoço tendeu a produzir menor MSR (Tabela 2). Esse comportamento, possivelmente, pode ter ocorrido devido ao baixo desenvolvimento dosistema radicular, principalmente, as raízes proteóides, que acidificam o ambiente da rizosfera, fazendo com que o P seja solubilizado (RAGHOTHAMA, 1999; MACHADO; FURLANI, 2004). Uma vez que o maior crescimento das raízes e/ou maior demanda de $\mathrm{Ca}^{+2}$, favorecerá uma maior remoção de $\mathrm{Ca}^{+2}$, fazendo com que aumente a taxa de dissolução do fosfato natural (NOVAIS; SMYTH, 1999).

Quanto à relação MSPA/MSR, verificou-se as maiores relações com o uso de FNA do que com o ST, embora significativo apenas para Brachiaria decumbens e o tremoço (Tabela 2). Com relação às plantas de cobertura, observou-se que a aveia preta e tremoço tiveram maiores valores tanto com o uso de ST como FNA, embora significativo apenas para o tremoço. Estes resultados estão em função principalmente da menor produção de MSR em relação à MSPA, a qual foi consideravelmente reduzida com o uso do FNA, exceto para o tremoço, o qual produziu maior MSPA, embora sem diferença estatística das outras espécies (Tabela 2).

Marschner (1995) e Rao, Ayarza e Garcia (1995), destacaram que em relação à parte aérea, o crescimento das raízes é menos limitado na condição de deficiência de P. Quando o P limita em particular o crescimento vegetal, as raízes exibem um comportamento de forte dreno de carboidratos, causando maior limitação ao crescimento da parte aérea do que da raiz. Essa redução do crescimento da parte aérea ocorre logo após o início da deficiência de $\mathrm{P}$, enquanto o crescimento radicular só é afetado após um maior intervalo de tempo, e com menor intensidade (FREDEEN; RAO; TERRY, 1989; ZONTA et al., 2006).

Quanto ao teor, acúmulo na parte aérea e índice de eficiência de utilização de $\mathrm{P}$ (IEU), houve diferenças significativas das fontes de $\mathrm{P}$ e também entre as plantas de cobertura. Observou-se que os teores de $\mathrm{P}$ foram menores com a aplicação de ST, com exceção do tremoço, o qual não se notou diferença entre as fontes de $\mathrm{P}$.

Para o acúmulo de $\mathrm{P}$ e IEU, em todas as plantas estudadas, o uso do ST proporcionou maiores médias em relação ao FNA (Tabela 3 ).

Tabela 3. Teor, acúmulo e índice de eficiência de utilização de fósforo na parte aérea das plantas de cobertura cultivadas sob fontes de P em um LATOSSOLO VERMELHO Distroférrico.

\begin{tabular}{|c|c|c|c|c|c|}
\hline \multirow[t]{2}{*}{ Forrageiras } & Teor de $\mathbf{P}$ & \multicolumn{2}{|c|}{ Acúmulo de $P$} & \multicolumn{2}{|c|}{ IEU } \\
\hline & ${ }^{3}$ FNA & ST & FNA & ST & FNA \\
\hline & -------g kg-1_------- & \multicolumn{2}{|c|}{-----mg vaso-1_------ } & \multicolumn{2}{|c|}{---g $\mathrm{gg}^{2}$ de P--- } \\
\hline Brachiaria brizantha & $0,76 \mathrm{cB} 11,58 \mathrm{bA}$ & $7,03 \mathrm{cdA}$ & $1,59 \mathrm{bB}$ & $11,5 \mathrm{aA}$ & $0,68 \mathrm{aB}$ \\
\hline Brachiaria decumbens & $0,83 \mathrm{bcB} 1,41 \mathrm{bA}$ & $8,69 \mathrm{bA}$ & $1,59 \mathrm{bB}$ & $12,89 \mathrm{aA}$ & $0,93 \mathrm{aB}$ \\
\hline Tanzânia & $0,84 \mathrm{bcB} \quad 1,83 \mathrm{aA}$ & $6,45 \mathrm{dA}$ & $1,38 \mathrm{bB}$ & $11,16 \mathrm{aA}$ & $0,41 \mathrm{aB}$ \\
\hline Aveia preta & $1,16 \mathrm{aB} \quad 1,50 \mathrm{bA}$ & $19,02 \mathrm{aA}$ & $2,07 \mathrm{abB}$ & $12,85 \mathrm{aA}$ & $0,88 \mathrm{aB}$ \\
\hline Tremoço & $1,07 \mathrm{abA} \quad 1,14 \mathrm{cA}$ & $8,12 \mathrm{bcA}$ & $3,03 \mathrm{aB}$ & $5,60 \mathrm{bA}$ & $1,67 \mathrm{aB}$ \\
\hline
\end{tabular}

(1) Médias seguidas pela mesma letra minúscula na coluna e maiúscula na linha não diferem entre si pelo teste de Tukey, a $5 \%$ de probabilidade. ${ }^{2} \mathrm{ST}$ - superfosfato triplo; ${ }^{3} \mathrm{FNA}$ - fosfato natural de araxá. 
Com a aplicação do ST o maior teor foliar de P foi alcançado pela aveia preta e pelo tremoço, ao contrário do que aconteceu com o FNA, onde o maior teor de $\mathrm{P}$ foliar foi obtido pelo capim tanzânia, que diferiu significativamente das demais espécies, seguido pelas braquiárias, pela aveia preta e pelo tremoço (Tabela 3 ). O acúmulo de $\mathrm{P}$ pela aveia preta, com o uso do ST, foi consideravelmente maior e com a aplicação do FNA, observou-se que a aveia preta, juntamente com o tremoço, teve as maiores extrações de P.

Observou que o tremoço teve menor IEU com a aplicação de ST, mas com o uso de FNA, embora sem diferença significativa, houve uma tendência de melhor utilização de $\mathrm{P}$ com a fonte menos solúvel (Tabela 3 ).

Os menores teores foliares de P na parte aérea foram obtidos pelas gramíneas as quais tiveram as maiores produções de massa seca da parte aérea (Tabela 2), com o uso do $\mathrm{ST}$, em relação ao FNA, caracterizando assim o efeito de diluição, que consiste na redução da concentração de um nutriente no tecido foliar ao nível de deficiência em função do aumento da taxa de crescimento do vegetal (JARREL; BEVERLY, 1981). Comportamento semelhante foi observado por Faquin et al. (1997), quando estudaram o efeito da aplicação de calcário e fontes de $\mathrm{P}$ na nutrição do Braquiarão ( Brachiaria brizantha) em amostras de latossolo da região dos Campos da Vertente no estado de Minas Gerais. A aveia preta, ao contrário do observado para as gramíneas, produziu mais MSPA e detectou-se maior teor de P com o uso do ST. Já no tremoço, observou-se menor produção de MSPA dentre todas as espécies, com o uso de ST, mas o teor de P praticamente não difere do encontrado para a aveia preta. Ainda sobre o tremoço, observase que o mesmo produziu mais MSPA com o uso de FNA, mas com menor teor foliar de $\mathrm{P}$ (Tabelas 2 e 3 ) do que as espécies em estudo. Vale destacar ainda, que ao se comparar as fontes de $\mathrm{P}$, detectou-se no tremoço uma tendência de maior teor foliar com o uso de FNA, embora sem diferença significativa, conforme comentado acima.

$\mathrm{O}$ alto acúmulo de $\mathrm{P}$ e IEU pela aveia preta com a aplicação de ST demonstra ser uma alternativa promissora para a ciclagem de $\mathrm{P}$, durante a entressafra e em virtude de sua baixa taxa de decomposição, proporciona melhor cobertura ao solo (PERIN et al., 2004). Também deve ser corroborado o potencial do tremoço, uma vez que com o uso de FNA, fonte de P de baixa solubilidade, apresenta um dos maiores valores de acúmulo de $\mathrm{P}$ na parte aérea e o maior índice de utilização de $\mathrm{P}$ dentre as espécies estudadas. Isso implica no potencial que o tremoço poderá ter, para inibir a fixação desse elemento nos solos da região do cerrado, no geral, considerado dreno de $\mathrm{P}$ e, proporcionar a maior eficiência de uso das fontes de $\mathrm{P}$ de baixa solubilidade, como o FNA pelas culturas agrícolas.

\section{Neossolo quartzarênico (RQo)}

Observou-se que com a aplicação do FNA, o tremoço expressou maior produção de MSPA e MSR e não houve diferença entre as demais plantas de cobertura (Tabela 4). Assim como observado no LVdf, com a aplicação do ST, a aveia preta atingiu a maior produção de MSPA. As braquiárias e o capim tanzânia foram as forrageiras que produziram mais MSR com o uso do ST. Em relação às fontes, com o uso do $\mathrm{ST}$, verificaram-se maiores produções tanto de MSPA como de MSR, o que era esperado, por se tratar de uma fonte de alta solubilidade. 
Tabela 4. Produção de massa seca na parte aérea (MSPA) e raiz (MSR) e a relação parte aérea/raiz (MSPA/ MSR) das plantas de cobertura sob fontes de P em um NEOSSOLO QUARTZARÊNICO.

\begin{tabular}{|c|c|c|c|c|c|c|}
\hline \multirow[t]{2}{*}{ Forrageiras } & \multicolumn{2}{|c|}{ MSPA } & \multicolumn{2}{|c|}{ MSR } & \multicolumn{2}{|c|}{ MSPA/MSR } \\
\hline & ${ }^{2} \mathbf{S T}$ & 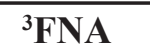 & ST & FNA & ST & FNA \\
\hline & ....................... & ............g.v & (................... & ....... & - & \\
\hline Brachiaria brizantha & $7,59 \mathrm{cA}^{1}$ & $0,25 \mathrm{bB}$ & $9,25 \mathrm{aA}$ & $0,21 \mathrm{bB}$ & $0,82 \mathrm{cB}$ & $1,16 \mathrm{cA}$ \\
\hline Brachiaria decumbens & $10,05 \mathrm{bA}$ & $0,60 \mathrm{bB}$ & $9,51 \mathrm{aA}$ & $0,50 \mathrm{bB}$ & $1,06 \mathrm{cA}$ & $1,20 \mathrm{cA}$ \\
\hline Tanzânia & $7,40 \mathrm{cA}$ & $0,15 \mathrm{bB}$ & 9,48 aA & $0,15 \mathrm{bB}$ & $0,78 \mathrm{cA}$ & $0,89 \mathrm{cA}$ \\
\hline Aveia preta & $15,61 \mathrm{aA}$ & $0,46 \mathrm{bB}$ & $4,74 \mathrm{bA}$ & $0,24 \mathrm{bB}$ & $3,09 \mathrm{aA}$ & $1,89 \mathrm{bB}$ \\
\hline Tremoço & $7,74 \mathrm{cA}$ & $5,45 \mathrm{aB}$ & $4,15 \mathrm{bA}$ & $2,27 \mathrm{aB}$ & $1,86 \mathrm{bB}$ & $2,42 \mathrm{aA}$ \\
\hline
\end{tabular}

(1) Médias seguidas pela mesma letra minúscula na coluna e maiúscula na linha não diferem entre si pelo teste de Tukey, a $5 \%$ de probabilidade. ${ }^{2} \mathrm{ST}$ - superfosfato triplo; ${ }^{3} \mathrm{FNA}$ - fosfato natural de araxá.

Conforme relatado anteriormente, possivelmente o tremoço produziu raízes proteóides, as quais acidificam a rizosfera e favorecem a solubilização do FNA, uma vez que esta espécie produziu mais MSPA e MSR com o uso do FNA, além de maior relação entre MSPA e MSR. Observou-se também comportamento significativo no Neossolo Quartzarênico (Tabela 1), possivelmente favorecido por um maior desenvolvimento do tremoço em decorrência do baixo poder dreno de $\mathrm{P}$.

Para a relação MSPA/MSR, os maiores valores foram observados para a aveia preta, com o uso do ST. Quando se comparou as duas fontes, observou-se uma tendência de superioridade com o uso do FNA, exceto para aveia preta. Com aplicação do ST, a Brachiaria brizantha e o capim Tanzânia tiveram valores absolutos de MSR semelhantes a MSPA (Tabela 4). Esse mesmo comportamento foi observado por Costa et al. (2008) com Brachiaria brizantha, os quais relataram que o $\mathrm{P}$ prontamente disponível para a planta, oriundo de fontes solúveis promove maior crescimento radicular dessa forrageira. Explicação que pode ser utilizado para o capim
Tanzânia, uma vez que se trata de uma gramínea.

$\mathrm{O}$ menor teor de $\mathrm{P}$ foliar foi observado na Brachiaria decumbens e Brachiaria brizantha com o uso do ST, e para o FNA, os maiores teores foram obtidos pelo tremoço seguido pela a aveia preta (Tabela 5). Da mesma forma como observado no Latossolo, o acúmulo de $\mathrm{P}$ e o IEU foram maiores na aveia preta com a aplicação do ST e no tremoço com o uso do FNA. Vale destacar que o tremoço foi a única espécie onde o teor de P e IEU não diferiram estatisticamente em relação as fontes de P. Observa-se ainda que o ST proporcionou maiores teores, acúmulo e IEU de P nas plantas de cobertura (Tabela 5).

A superioridade na extração de $\mathrm{P}$ pela aveia preta com a aplicação de ST e do tremoço com FNA nos solos em estudo, é reflexo da maior produção de MSPA (Tabela 2 e 4) e dos teores de $\mathrm{P}$ (Tabelas 3 e 5) observado nestas forrageiras. Portanto, em sistemas de produção mais conservacionistas estas forrageiras seriam uma boa opção para entrarem na rotação de culturas, pois são promissoras tanto na produção de cobertura vegetal quanto na ciclagem de fósforo. 
Tabela 5. Teor, acúmulo e índice de eficiência de utilização de fósforo na parte aérea das plantas de cobertura influenciadas por fontes de P e cultivadas em um NEOSSOLO QUARTZARÊNICO.

\begin{tabular}{|c|c|c|c|c|c|c|}
\hline \multirow[t]{2}{*}{ Forrageiras } & \multicolumn{2}{|c|}{ Teor de $\mathbf{P}$} & \multicolumn{2}{|c|}{ Acúmulo de $\mathbf{P}$} & \multicolumn{2}{|c|}{ IEU } \\
\hline & ${ }^{2} \mathbf{S T}$ & ${ }^{3}$ FNA & ST & FNA & ST & FNA \\
\hline & \multicolumn{2}{|c|}{-------g kg-1-------- } & \multicolumn{2}{|c|}{-------mg vaso-1 -------- } & \multicolumn{2}{|c|}{----g' $\mathrm{mg}^{-1}$ de P---- } \\
\hline Brachiaria brizantha & $1,16 \mathrm{abA}^{1}$ & $0,42 \mathrm{cA}$ & $8,73 \mathrm{cA}$ & $0,09 \mathrm{bB}$ & $6,62 \mathrm{cA}$ & $0,67 \mathrm{bB}$ \\
\hline Brachiaria decumbens & $1,04 \mathrm{bA}$ & $0,84 \mathrm{bB}$ & $10,98 \mathrm{bA}$ & $0,49 \mathrm{bB}$ & $9,28 \mathrm{bA}$ & $0,73 \mathrm{bB}$ \\
\hline Tanzânia & $1,30 \mathrm{aA}$ & $0,41 \mathrm{cB}$ & $9,60 \mathrm{bcA}$ & $0,04 \mathrm{bB}$ & $5,75 \mathrm{cA}$ & $0,53 \mathrm{bB}$ \\
\hline Aveia preta & $1,32 \mathrm{aA}$ & $1,07 \mathrm{abB}$ & $18,63 \mathrm{aA}$ & $0,55 \mathrm{bB}$ & $11,52 \mathrm{aA}$ & $0,39 \mathrm{bB}$ \\
\hline Tremoço & $1,27 \mathrm{abA}$ & $1,14 \mathrm{aA}$ & $10,50 \mathrm{bA}$ & $5,26 \mathrm{aB}$ & $5,78 \mathrm{cA}$ & $5,73 \mathrm{aA}$ \\
\hline
\end{tabular}

Sem utilizar fontes de fósforo, mas apenas com o objetivo de quantificar os nutrientes reciclados por cinco espécies vegetais (aveia preta, mucuna preta, guandu, tremoço e ervilhaca) e o potencial de retorno dos nutrientes ao solo via mineraização da biomassa, Borkert et al. (2003) ao estudarem a quantidade estimada de nutrientes reciclados por espécies vegetais de cobertura do solo, encontraram para aveia preta uma quantidade de $\mathrm{P}$ entre 8 a 12 $\mathrm{kg} \cdot \mathrm{ha}^{-1}$ e para o tremoço de 16 a $19 \mathrm{~kg} \cdot \mathrm{ha}^{-1}$.

Segundo Rao et al. (1997) as diferenças entre gramíneas e leguminosas quanto à eficiência de aquisição e utilização de $\mathrm{P}$ podem ser explicadas pela morfologia do sistema radicular, eficiência de aquisição de $\mathrm{P}$ por unidade de raíz, atividade de fosfatase ácida e concentração de fósforo nas raízes e parte aérea. As gramíneas possuem um maior sistema radicular, enquanto as leguminosas têm maior eficiência de aquisição de P por unidade de raiz.

\section{Conclusões}

O superfosfato triplo (ST) proporcionou maior massa seca da parte aérea, das raízes e acúmulo de $P$ na parte aérea das plantas de cobertura nos solos estudados.

A aveia preta, com aplicação de ST e o tremoço com o fosfato natural de Araxá (FNA) mostraramse promissores na produção de cobertura vegetal e ciclagem de fósforo.

\section{Agradecimentos}

Ao Conselho Nacional de Desenvolvimento Científico e Tecnológico (CNPq) pelo apoio financeiro, para a realização deste trabalho.

\section{Referências}

ANDRADE, F. V.; MENDONÇA, E. S.; ALVAREZ, V. V. H.; NOVAIS, R. F. Adição de ácidos orgânicos e húmicos em. Latossolos e adsorção de fosfato. Revista Brasileira de Ciência do Solo, Viçosa, v. 22, n. 6, p. 1003-1011, 2003.

ARAÚJO, W. F.; SAMPAIO, R. A.; MEDEIROS, R. D. Resposta de cultivares de soja à adubação fosfatada. Revista Ciência Agronômica, Fortaleza, v. 36, n. 2, p. 129-134, 2005.

BEDIN, I.; FURTINI NETO, A. E.; RESENDE, A. V.; FAQUIN, V.; TOKURA, A. M.; SANTOS, J. Z. L. Fertilizantes fosfatados e produção da soja em solos com diferentes capacidades tampão de fosfato. Revista Brasileira de Ciência do Solo, Viçosa, v. 27, n. 4, p. 639646, 2003.

BORKERT, C. M.; GAUDÊNCIO, C. A.; PEREIRA, J. E.; OLIVEIRA JUNIOR, A. Nutrientes minerais na biomassa da parte aérea de culturas de cobertura de solo. Pesquisa Agropecuária Brasileira, Brasília, v. 38, n. 1, p. 143-153, 2003.

BRAGA, J. M.; DEFELIPO, B. V. Determinação espectrofotométrica de fósforo em extratos de solos e plantas. Revista Ceres, Viçosa, v. 21, n. 113, p. 73-85, jan./fev. 1974. 
CORREAA, R. M.; NASCIMENTO, C. W. A.; SOUZA, S. K. S.; FREIRE, F. J.; SILVA, G. B. Gafsa rock phosphate and triple superphosphate for dry matter production and P uptake by corn. Scientia Agrícola, Piracicaba, v. 62, n. 2, p. 159-164, 2005.

COSTA, S. E. V. G. A.; FURTINI NETO, A. E.; RESENDE,A. V.; SILVA, T. O.; SILVA, T. R. Crescimento e nutrição da braquiária em função de fontes de fósforo. Ciência e Agrotecnologia, Lavras, v. 32, n. 5, p. 14191427, 2008.

DUDA, G. P.; GUERRA, J. G. M.; MONTEIRO, M. T.; DE-POLLI, H.; TEIXEIRA, M. G. Perennial herbaceous legumes as live soil mulches and their effects on $\mathrm{C}, \mathrm{N}$ and P of the microbial biomass. Scientia Agrícola, Piracicaba, v. 60, n. 1, p. 139-147, 2003.

FAQUIN, V.; ROSSI, C.; CURI, N.; EVANGELISTA, A. R. Nutrição mineral em fósforo, cálcio e magnésio do Braquiarão em amostras de Latossolo dos Campos das Vertentes sob influência de calagem e fontes de fósforo. Revista Brasileira de Zootecnia, Viçosa, v. 26, n. 6, p. 1074-1082, 1997.

FERNANDES, C.; MURAOKA, T. Absorção de fósforo por híbridos de milho cultivados em solos de cerrado. Scientia Agrícola, Piracicaba, v. 59, n. 4, p. 781-787, 2002.

FERREIRA, D. F. Análises estatísticas por meio do Sisvar para Windows versão 4.0. In: REUNIÃO ANUAL DA REGIÃO BRASILEIRA DA SOCIEDADE INTERNACIONAL DE BIOMETRIA, 45., 2000, São Carlos, SP. Programa e resumos...São Carlos: UFscar, 2000. p. 255-258.

FOHSE, D.; CLASSEN, N.; JUNGK, A. Phosphorus efficiency of plants. I. external and internal P requeriments and $\mathrm{P}$ uptake efficiency of different plant species. Plant and Soil, The Hague, v. 110, p. 101-109, 1988.

FREDEEN, A. L.; RAO, I. M.; TERRY, N. Influence of phosphorus nutrition on growth and carbon partitioning in Glycine max. Plant Physiol., v. 89, n. 2, p. 225-230, 1989.

JARREL, W. M.; BEVERLY, R. B. The dilution effect in plant nutrition studies. Advances in Agronomy, New York, v. 34, n. 1, p. 197-224, 1981.

MACHADO, C. T. T.; FURLANI, A. M. C. Root phosphatase activitivy, plant growth and phosphorus accumulation of maize genotypes. Scientia Agrícola, Piracicaba, v. 61, n .2, p. 216-223, 2004.

MALAVOLTA, E.; VITTI, G. C.; OLIVEIRA, S. A. Avaliação do estado nutricional das plantas: princípio e aplicações. 2. ed. Piracicaba: POTAFOS, 1997. 319 p.
MARSCHNER, H. Mineral nutrition of higher plants. London: Academic Press, 1995. 889 p.

NOVAIS, R. F.; SMYTH, T. J. Fósforo em solo e planta em condições tropicais. Viçosa, MG: UFV, DPS, 1999. $399 \mathrm{p}$.

OLIVEIRA, F .H. T.; NOVAIS, R. F.; ALVAREZ, V. V. H.; CANTARUTTI, R. B.; BARROS, N. F. Fertilidade do solo no sistema plantio direto. Tópicos em Ciência do Solo, Viçosa, v. 2, p. 393-486. 2002.

PERIN, A. Desempenho de leguminosas herbáceas perenes com potencial de utilização para cobertura viva e seus efeitos sobre alguns atributos fisicos do solo. 2001. Tese (Mestrado em Ciência do Solo) - Universidade Federal Rural do Rio de Janeiro, Seropédica.

PERIN, A.; SANTOS, R. H. S.; URQUIAGA, S.; GUERRA, J. G.; CECON, P. R. Produção de fitomassa, acúmulo de nutrientes e fixação biológica de nitrogênio por adubos verdes em cultivo isolado e consorciado. Pesquisa Agropecuária Brasileira, Brasília, DF, v. 39, n. 1, p. 35-40, 2004.

RAGHOTHAMA, K. G. Phosphate acquisition. Annu. Rev. Plant Physiol Plant Mol. Biol., v. 50, p. 665-693, 1999.

RAO, I. M.; AYARZA, M. A.; GARCIA, R. Adaptive attributes of tropical forage species to acid soils. I. Differences in plant growth, nutrient acquisition and nutrient utilization among $\mathrm{C} 4$ grasses and $\mathrm{C} 3$ legumes. Journal of Plant Nutrition, New York, v.18, n. 10, p. 2135-2155, 1995.

RAO, L. M.; BORRETO, V.; RICAURTE, J.; GARCIA, R.; AYARZA, M. A. Adaptive attributes of tropical forage species to acid soils. III. Differences in phosphorus acquisition and utilization as influenced by varying phosphorus supply and soil type. Journal of Plant Nutrition, New York, v. 20, n. 1, p. 155-180, 1997.

SARMENTO, P.; CORSI, M.; CAMPOS, F. P. Resposta da alfafa a fontes de fósforo associadas ao gesso e à calagem. Scientia Agrícola, Piracicaba, v. 58, n. 2, 2001. p. 381-390.

SIDDIQI, M. Y.; GLASS, A. D. M. Utilization índex: a modified approach to the estimations and comparison of nutrient utilization efficiency in plants. Journal of Plant Nutrition, New York, v. 4, n. 3, p. 289-302, 1981.

SILVA, F. N.; FURTINI NETO, A. E.; CARNEIRO, L. F.; MAGAlHÃES, C. A. S.; CARNEIRO, D. N. M. Crescimento e produção de grãos da soja sob diferentes doses e fontes de fósforo em solos distintos. Ciência e Agrotecnologia, Lavras, v. 33, n. 5, p. 1220-1227, 2009.

SOARES, I.; LIMA, S. C.; CRISÓSTOMO, L. A. 
Crescimento e composição mineral de mudas de gravioleira em resposta a doses de fósforo. Revista Ciência Agronômica, Fortaleza, v. 38, n. 4, p. 343-349, 2007.

SOUSA, D. M. G.; LOBATO, E.; REIN, T. A. Adubação com fósforo. In: SOUSA, D. M. G.; LOBATO, E. (Ed.). Cerrado: correção do solo e adubação. 2. ed. Brasília, DF: Embrapa Informação Tecnológica, 2004. p.147-168.

ZONTA, E.; BRASIL, F. C.; GOI, S. R.; ROSA, M. M. T. O sistema radicular e suas interações com o ambiente edáfico. In: FERNANDES, M. S. (Ed.). Nutrição mineral de plantas. Viçosa: Sociedade Brasileira de Ciência do Solo, 2006. p. 8-52. 
